\title{
Estimation of the Dominance Variance for Postweaning Gain in the U.S. Limousin Population ${ }^{1}$
}

\author{
N. Gengler2,3, I. Misztal, J. K. Bertrand, and M. S. Culbertson 4 \\ Department of Animal and Dairy Science, University of Georgia, Athens 30602
}

\begin{abstract}
The objective of this study was to estimate the dominance variance for postweaning gain in Limousin cattle. Data included 215,326 records of postweaning gain from 205 to $365 \mathrm{~d}$, provided by the North American Limousin Foundation. Parental dominance subclasses were formed and related using the method of Hoeschele and VanRaden. Variance components were estimated using Method $\Re$ based on six samples of $50 \%$. Fixed effects in the model included contemporary group and covariates for inbreeding and breed composition (percentage Limousin). Heterozygosity was negatively correlated with breed composition $(<-.99)$ and was therefore not included in the model. Two types of contemporary groups used as original groups from the National Cattle Evaluation were partially based on breed composition. Original contemporary groups that were too homogeneous for breed composition were replaced by herd-year-sex classes. Two models were used with the two data sets. Model 1 contained the fixed effects described above and an additive genetic effect. Model 2 included a
\end{abstract}

dominance effect in addition to the effects contained in Model 1. In total, four combinations of contemporary group $\times$ model were used. Dominance variance was computed as being four times the estimated parental subclass variance. Estimates for inbreeding depression and breed composition (percentage Limousin) were all small and not greatly affected by inclusion of dominance effects or changes in contemporary groups. Estimates of the additive variance (expressed as percentage of the phenotypic variance) were only slightly affected, with values between 20 and $21 \%$. Dominance estimates were highly affected when passing from original (10\%) and to alternative contemporary groups (18\%). Such large values may indicate that dominance is important for postweaning gain. Results showed the advantage of an individual dominance approach based on sire-dam combinations; therefore, expected gains through the use of specific combination ability as a part of the mating selection criteria for growth might be high.

Key Words: Limousin, Postweaning Interval, Dominance, Genetic Parameters

@1998 American Society of Animal Science All rights reserved.

J. Anim. Sci. 1998. 76:2515-2520

\section{Introduction}

The U.S. Limousin population was created partly through imports of animals and semen of French origin. Most animals trace back to original beef breed females upgraded with Limousin males. Some of the

\footnotetext{
${ }^{1}$ The authors wish to acknowledge that the North American Limousin Foundation, Englewood, CO 80155 provided the data for this study. They also thank Ab Groen, Wageningen Agricultural University, Wageningen, The Netherlands, for manuscript review.

${ }^{2}$ The senior author, who is Chargé de Recherches of the Fonds National Belge de la Recherche Scientifique, Belgium, acknowledges its financial support.

${ }^{3}$ Current address: Faculté Universitaire des Sciences Agronomiques, B-5030 Gembloux, Belgium; phone: +32/81/622206; fax: +32/ 81/622115; E-mail: gengler.n@fsagx.ac.be.

${ }^{4}$ Current address: Cotswold USA, 15491 State Hwy. 941, Alden, I owa 50006-9103.

Received December 17, 1997.

Accepted J une 1, 1998.
}

descendants are reaching percentages of Limousin (PCTL) inheritance that qualify them for North American Limousin Foundation (NALF) purebred status ( $>87$ PCTL for females and > 93 PCTL for males). Animals that descend directly from 100 PCTL animals of French origin are called fullbloods or imported animals by NALF.

Current genetic evaluations use additive genetic models, as for postweaning gain (PWG) in U.S. Limousin. The most important nonadditive effect is the dominance effect. However, setting up the inverted dominance relationship matrix $\mathbf{D}^{-1}$ is difficult. Only since Hoeschele and VanRaden (1991) replaced the D $^{-1}$ matrix with the inverted sire-dam subclass relationship matrix $\mathbf{F}^{-1}$, which gives the dominance covariances between sire-dam subclasses, have dominance models become feasible. Recent studies for dominance using large cattle populations have been reported only for dairy cattle (e.g., Misztal et al., 1997a); whereas, studies with beef cattle have been 
limited to small populations (e.g., Rodriguez-Almeida, 1995; Gengler et al., 1997).

Other concepts related to dominance variance are heterosis and inbreeding. Heterosis can be described as a mean nonadditive effect that is due to interaction among different alleles coming from parental breeds. Inbreeding is the probability that homozygous alleles at a locus are identical by descent from an ancestral allele, and it is associated with a reduction in total genetic variance and depression in phenotypic performance. E fforts have been made to unify the concept of inbreeding and heterosis (VanRaden, 1992) by extending the additive relationship matrix beyond base animals using a relationship matrix among breeds. Dominance variance can then be considered a measure of individual allele interaction on specific loci.

Our objective was to expand knowledge of dominance for PWG in the upgrading population of U.S. Limousin, as any observed dominance variance could be evidence that specific combining ability in beef cattle could be exploited.

\section{Materials and Methods}

\section{Materials}

Postweaning gain records were obtained from NALF and extracted from the National Cattle Evaluation data base at the University of Georgia, Athens. Postweaning gain was measured between 205 and 365 $d$ of age. Data were from the same data set used in the August 1996 genetic evaluation for NALF.

Pedigrees were extracted directly from the NALF herdbook. Percentage Limousin figures were obtained for all calves, sires, and dams. Percentage Limousin was checked using the animal identification prefixes, which reference genetic origin (French, Canadian, U.S., level of upgrading status) and was compared to the mean of the PCTL of the sire and dam. A few errors were detected and corrected. Extended pedigree files that were traced back to the first ancestors of the animals in the NALF herdbook contained 507,430 animals. Of these animals, 43,488 had at least one unknown parent, with $91.6 \%$ of them being nonLimousin foundation animals (approximately $99.8 \%$ of these animals were females); $6.1 \%$ NALF purebred, fullblood (100 PCTL), or imported Limousin (close to $61.2 \%$ of these animals were of French origin); and only $2.3 \%$ were animals considered crossbreds.

Parental dominance subclasses were formed and related using the method of Hoeschele and VanRaden (1991). A total of 580,233 classes were created. Heterosis, expressed as heterozygosity (HET), was estimated for all animals with records using the approach that is usually used (e.g., VanRaden, 1992) for the description of HET for a given animal A:

$$
\begin{aligned}
\mathrm{HET}_{\mathrm{A}}= & (\mathrm{PCTL} / 100)+\left(\mathrm{PCTL} L_{\mathrm{D}} / 100\right)- \\
& 2 \cdot\left(\mathrm{PCTL} L_{S} \cdot \mathrm{PCTL} L_{D}\right) / 10,000
\end{aligned}
$$

where PCTL $L_{S}$ and PCTL $L_{D}$ are the percentage Limousin of the sire and dam. Unfortunately, the definition of HET and PCTL are very closely linked, as is shown by the formula to compute PCTL of an animal A:

$$
\mathrm{PCTL}_{\mathrm{A}}=(\mathrm{PCTL} / 2)+\left(\mathrm{PCTL} L_{\mathrm{D}} / 2\right)
$$

Theoretically, HET and PCTL effects can be clearly distinguished only if, together with crossbred animals, 0 and 100 PCTL animals have a record themselves (e.g., Sölkner and J ames, 1990). In our case, only some fullblood (100 PCTL) or imported Limousin animal performance records were present (Table 1 ), because a minimum level of 37 PCTL is required by NALF to include the record in their data base. Therefore, before deciding on the inclusion of the PCTL and HET in a model, correlations between $\mathrm{PCTL}_{A}, \mathrm{PCTL}_{S}, \mathrm{PCTL}_{D}$, and $\mathrm{HET}_{\mathrm{A}}$ were studied in order to avoid confounding.

In the grading-up process, few bulls with less than 100 PCTL were used; hence, recombination loss was not modeled. No distinction was made between breeds other than Limousin because data files provided limited information on base animals. Also, most upgrading was based on British-type cattle; therefore, considering all 0 PCTL animals as if they were of British breed origin should be sufficient for this study.

Inbreeding was computed for all animals with a simplified method based on the rules presented by VanRaden (1992), using one cycle to estimate inbreeding for animals with unknown parents instead of iterating on the computed inbreeding for these animals. This approach may have resulted in a small but irrelevant underestimation of inbreeding as reported by VanRaden (1992). Because inbreeding was probably mostly in animals with high PCTL, the eventual confounding for inbreeding and PCTL was tested by studying the correlations among inbreeding and the PCTL for the animals and their sires and dams.

\section{Models}

The following two models were used.

$$
\begin{aligned}
& \mathbf{y}=\mathbf{X b}+\mathbf{Z a}+\mathbf{e} \\
& \mathbf{y}=\mathbf{X b}+\mathbf{Z a}+\mathbf{W d}+\mathbf{e}
\end{aligned}
$$

where

$$
\begin{aligned}
\mathbf{y}= & \text { PWG (in } \mathrm{kg} \text { ); } \\
\mathbf{b}= & \text { an unknown vector of fixed contem- } \\
& \text { porary group effects, regression coeffi- } \\
& \text { cients on inbreeding, on PCTL, and } \\
& \text { eventually on HET; } \\
\mathbf{X}= & \text { a known incidence matrix relating } \mathbf{y} \\
& \text { and } \mathbf{b} ; \\
\mathbf{a}= & \text { an unknown vector of random additive } \\
& \text { direct effects of the animal; }
\end{aligned}
$$




$$
\begin{aligned}
\mathbf{Z}= & \text { a known incidents matrix linking } \\
& \text { records and animals; } \\
\mathbf{d}= & \text { an unknown vector of parental sub- } \\
& \text { class dominance effects; } \\
\mathbf{w}= & \text { a known incidence matrix linking } \mathbf{y} \\
& \text { and } \mathbf{d} ; \\
\mathbf{e}= & \text { an unknown vector of uncorrelated } \\
& \text { residual effects. }
\end{aligned}
$$

Variance and covariance of $\mathbf{a}, \mathbf{d}$, and e were

$$
\operatorname{var}\left[\begin{array}{l}
\mathbf{a} \\
\mathbf{d} \\
\mathbf{e}
\end{array}\right]=\left[\begin{array}{lll}
\mathbf{A} \boldsymbol{\sigma}_{\mathrm{a}}^{2} & \mathbf{0} & \mathbf{0} \\
\mathbf{0} & \mathbf{F} \boldsymbol{\sigma}_{\mathrm{f}}^{2} & \mathbf{0} \\
\mathbf{0} & \mathbf{0} & \mathbf{I} \boldsymbol{\sigma}_{\mathrm{e}}^{2}
\end{array}\right]
$$

where $\sigma_{a}^{2}$ is the additive variance, $\sigma_{\mathrm{f}}^{2}$ is the parental dominance variance and thus is $1 / 4$ of the total dominance variance $\sigma_{\mathrm{d}}^{2}, \sigma_{\mathrm{e}}^{2}$ is the residual variance, $\mathbf{A}$ is the additive relationship matrix, and $\mathbf{F}$ is the parental subclass dominance relationship matrix. Inbreeding was considered in the construction of $\mathbf{A}^{-1}$ but not in the construction of $\mathbf{F}^{-1}$. The inverse of the parental dominance subclass matrix $\mathbf{F}^{-1}$ was computed according to the algorithm presented by Hoeschele and VanRaden (1991). Constructing $\mathbf{F}^{-1}$ to consider inbreeding is not yet feasible for large populations. However, in an upgrading population, where mean inbreeding is limited, ignoring inbreeding in the construction of $\mathbf{F}^{-1}$ should have little impact on the results.

Two types of contemporary groups were used: original groups from the National Cattle Evaluation (I) and an alternative grouping (II). The reason that this alternative grouping was tested lay in how the National Cattle Evaluation contemporary groups were formed. These groups were also partially based on PCTL, and they were therefore possibly confounded with other effects depending on PCTL. The following strategy was used to reassign alternative contemporary groups. First, for every National Cattle Evaluation contemporary group, the standard deviation of PCTL of the animals in the group was computed. If the standard deviation was less than 1 PCTL for at least one of the National Cattle Evaluation contem- porary groups inside a given herd-year-sex class, all the groups were replaced by this single herd-year-sex class; if this was never the case inside a herd-year-sex; the original groups were kept. Therefore, the alternative grouping can be considered the best compromise between replacing all groups by herd-year-sex and the old original National Cattle Evaluation contemporary groups. In total, four combinations of contemporary group $\times$ model were used, called hereafter Models I.1, I.2, II.1, and II.2.

Variance Component Estimation and Empirical Standard Errors

Estimates of variance components were obtained by Method $\Re$ (Reverter et al., 1994) following the procedures by Misztal (1997). Postweaning gain was analyzed with six samples of $50 \%$ from the whole data selected by a random number generator. The convergence criterion was $r_{i}=1 \pm .0001$, where $r_{i}$ is the regression for random effect i. Empirical standard error was defined as observed sampling error and was computed as the standard deviation of the six estimates from the subsamples.

\section{Results and Discussion}

\section{Descriptive Statistics}

Means, standard deviations, minimum and maximum values for breed composition (PCTL), inbreeding, heterozygosity coefficient, and PWG are given in Table 1. Mean PCTL of the animals showed that "on average" Limousin sires had been used for two to three generations. A minimum level of 37 PCTL was required to include the record in the data base. As expected, average dam PCTL was one generation behind the animals, and most sires used were 100 PCTL. Percentage of inbreeding was very limited, which would be expected in an upgrading population. The population showed important variation in heterozygosity with a mean value that was close to the value of one or two backcrosses to Limousin (.5 to .25). Mean PWG was $129.6 \mathrm{~kg}$, with extreme values below .2 kg and over $2 \mathrm{~kg}$ of gain/d.

Table 1. Descriptive statistics of records

\begin{tabular}{lcccc}
\hline \hline Item & Mean & $\begin{array}{l}\text { Standard } \\
\text { deviation }\end{array}$ & Minimum & Maximum \\
\hline Breed composition, \% Limousin & & & & \\
Animal & 79.2 & 18.5 & 37 & 100 \\
Sire & 98.4 & 3.7 & 50 & 100 \\
Dam & 60.2 & 37.3 & 0 & 100 \\
Inbreeding, \% & 1.00 & 2.54 & .0 & 39.0 \\
Heterozygosity & .406 & .364 & .00 & 1.00 \\
Postweaning gain, $\mathrm{kg}$ & 129.6 & 50.8 & 21.8 & 385.0 \\
\hline
\end{tabular}


Table 2. Correlation among inbreeding and heterozygosity and breed compositions (percentage Limousin) of the animals with records, and their sires and dams

\begin{tabular}{|c|c|c|c|c|}
\hline \multirow[b]{2}{*}{ Item } & \multicolumn{2}{|c|}{ Animal } & \multicolumn{2}{|c|}{$\begin{array}{l}\text { Breed composition, } \\
\% \text { Limousin }\end{array}$} \\
\hline & Inbreeding & Heterozygosity & Animal & Sire \\
\hline \multicolumn{5}{|c|}{ Breed composition, \% Limousin } \\
\hline Animal & 272 & -.995 & & \\
\hline Sire & -.135 & .125 & -.055 & \\
\hline Dam & .282 & -.998 & .995 & -.150 \\
\hline
\end{tabular}

Correlations Among Inbreeding, Heterozygosity, and Breed Composition

Table 2 shows the correlations among inbreeding and HET of the animals with records and PCTL of animal, sire, and dam. Inbreeding was only moderately correlated to PCTL; therefore, no important confounding was expected between those effects. However, the values for HET of the animal and its PCTL were highly linked, showing a correlation of nearly $-1(<-.99)$. A way to explain this correlation is by considering the correlations among the HET of the animal and the PCTL of its sire and dam. Results presented in Table 2 show a very high negative correlation $(<-.99)$ between HET and PCTL of the dam but only a small positive correlation of PCTL of the sire with HET. Also, the correlations among PCTL for animals, sires, and dams are interesting. Correlations were slightly negative between PCTL of animal and sire and PCTL of sire and dam. Correlation between PCTL of animal and PCTL of dam was very high (>.99). These results can be explained by the fact that nearly all sires used were $100 \mathrm{PCTL}$, and sire use was not dependent on PCTL of its mate.

Because of the extremely high negative correlation between PCTL and HET for a given animal, PCTL and HET were considered as being highly confounded; therefore, HET was not included in the model.

\section{Contemporary Groupings}

Table 3 shows the repartition of contemporary groups according to the variability (standard deviation) of PCTL. Of the original National Cattle Evaluation contemporary groups, approximately 63\% were not informative; the alternative grouping reduced this figure to approximately $40 \%$. Highly informative groups (standard deviation of PCTL >5) were very rare with the original groups ( $4 \%$ ) but were approximately four times more frequent (17\%) with the alternative groups.

Regression Coefficients

and Variance Components

Regression Coefficients. The influence of inbreeding depression is shown in Table 4. Results were nearly identical for all models. Inbreeding depression was
$240 \mathrm{~g}$ per percentage of inbreeding with Models I.1 and 1.2. An animal that was $12.5 \%$ inbred would have a PWG that is $3 \mathrm{~kg}$ less. Estimates of the regression coefficients for breed composition are also in Table 4. Difference between an animal with 100 PCTL and one with 0 PCTL was estimated to be between $1.27 \mathrm{~kg}$ with Model I.1 and $2.75 \mathrm{~kg}$ with Model II.2. This represented only 1 to $2 \%$ of the mean PWG, but the effect of PCTL was underestimated because heterosis was confounded with this effect. Indeed, putting dominance effects into the model seemed to reduce this underestimation. Also, alterative contemporary groups increased estimates of the effect of PCTL because it reduced confounding between contemporary groups and PCTL.

Additive Effects. Mean estimates of additive variance together with their empirical standard errors based on the standard deviation of the six estimates are given in Table 4. Additive genetic variances (expressed as percentage of phenotypic variance) were similar for Model I.1 (additive only) and Model I.2 (additive and dominance) with estimates of $21 \pm$ $1.1 \%$. This result was similar to results using the same data and an additive sire-maternal grandsire model (J . K. Bertrand, unpublished results). Also, the stability of the mean estimates seemed to indicate that the introduction of dominance in the model did not reduce the additive variance.

Alternative contemporary groups did not alter these results substantially, with values between $21 \pm 1.0 \%$ for Model II.1 (additive only) and $20 \pm .6 \%$ for Model II.2 (additive and dominance).

Dominance Effects. Estimates of dominance variance are also given in Table 4. For the original contemporary groups (Model I.2), the relatively high value for dominance variance of $10 \pm 1.4 \%$ was found, representing approximately $50 \%$ of the additive variance. It is not yet commonly accepted, but recent results show growth traits to have high absolute dominance variance as well as large ratios of dominance relative to additive values. For example, Misztal et al. (1997b) showed that absolute dominance variances were nearly $10 \%$ of the phenotypic variance and that the ratio of dominance to additive reached nearly $30 \%$ for strength and body depth in dairy cattle. In swine, Culbertson et al. (1998) showed that days to $104.5 \mathrm{~kg}$ had absolute 
Table 3. Distribution of variability (expressed as intragroup standard deviation) for percentage Limousin in original and alternative contemporary groups

\begin{tabular}{lrrrr}
\hline \hline & \multicolumn{3}{c}{ Number of contemporary groups } \\
\cline { 2 - 5 } Variability of \% Limousin & \multicolumn{2}{c}{ Original } & \multicolumn{2}{c}{ Alternative } \\
\hline$<1$ & 23,262 & $63.23 \%$ & 8,066 & $39.50 \%$ \\
$1-5$ & 12,146 & $33.01 \%$ & 8,883 & $43.50 \%$ \\
$6-10$ & 1,302 & $3.54 \%$ & 2,221 & $10.88 \%$ \\
$11-20$ & 68 & $.18 \%$ & 1,068 & $5.22 \%$ \\
$21-35$ & 13 & $.04 \%$ & 184 & $.90 \%$ \\
Total & 36,791 & & 20,422 & \\
\hline
\end{tabular}

dominance variances that were also nearly $10 \%$ of the phenotypic variance, and the ratio of dominance to additive reached over $30 \%$. The results from the current study showed the same trends.

With the alternative groups, the estimated dominance variance (Model II.2) was extremely high (18 $\pm 1.8 \%$ ). This value is indeed exceptional because it represents $94 \%$ of the additive estimate. This may be explained in different ways. First, the original groups masked dominance variance that was underestimated with Model I.2. This explanation would consider the estimate from Model II.2 as closer to the true one. But the opposite might be true (i.e., variation accounted for by the original groups was at least partially integrated into the dominance variance). A potential candidate for such variation in PWG could be the performance differences between males and females (R. L. Quaas, personal communication), but this cannot be the case here because both ways of grouping were separating males and females.
Another potential explanation might be elucidated indirectly through some theoretical thought. The method described by Lo et al. (1997) is very similar to the additive and dominance model used in the present study, only they distinguished between parental breed specific additive variances and additive covariances across breeds. In the case of the present study, the additive part was simplified by assuming constant additive variances and covariances, which can be defended in upgrading populations where the original germplasm is replaced by the new one; therefore, additive genetic variance is essentially that of Limousin. The model of Lo et al. (1997) did not include heterosis. Indeed, heterosis can be defined as mean breed interaction, and they modeled sire $\times$ dam interactions representing parental breed interactions as parental dominance subclasses using the parental dominance relationship matrix. This supports our decision to avoid fitting heterosis into our model because it is a simplified version of the model of $L o$ et

Table 4. Estimates of regression coefficients and variance components obtained from six runs of Method $\mathfrak{R}$

\begin{tabular}{|c|c|c|c|c|}
\hline \multirow[b]{2}{*}{ Groups } & \multirow{2}{*}{$\begin{array}{l}\text { Inbreeding } \\
\text { depression, } \\
\text { per \% }\end{array}$} & \multirow{2}{*}{$\begin{array}{c}\text { Breed } \\
\text { composition, } \\
\text { per } \% \\
\text { Limousin }\end{array}$} & \multicolumn{2}{|c|}{$\begin{array}{c}\text { Variance, } \\
\% \text { of phenotypic }\end{array}$} \\
\hline & & & Additive & Dominance \\
\hline \multicolumn{5}{|c|}{ Original contemporary } \\
\hline \multicolumn{5}{|c|}{ Additive model (Model I.1) } \\
\hline Mean & -.24 & .0127 & 21.2 & - \\
\hline Empirical SEa & .001 & .0025 & 1.1 & - \\
\hline \multicolumn{5}{|c|}{ Dominance model (Model I.2) } \\
\hline Mean & -.24 & .0175 & 20.6 & 10.3 \\
\hline Empirical $\mathrm{SE}^{\mathrm{a}}$ & .001 & .0003 & 1.1 & 1.4 \\
\hline \multicolumn{5}{|c|}{ Alternative contemporary } \\
\hline \multicolumn{5}{|c|}{ Additive model (Model II.1) } \\
\hline Mean & -.21 & .0258 & 20.6 & - \\
\hline Empirical $\mathrm{SE}^{\mathrm{a}}$ & .001 & .0010 & 1.0 & - \\
\hline \multicolumn{5}{|c|}{ Dominance model (Model II.2) } \\
\hline Mean & -.23 & .0273 & 19.5 & 18.4 \\
\hline Empirical $\mathrm{SE}^{\mathrm{a}}$ & .001 & .0002 & .6 & 1.8 \\
\hline
\end{tabular}

${ }^{a}$ Empirical SE = empirical standard error defined as observed sampling error, and computed as the standard deviation of the six estimates. 
al. (1997), and heterosis is replaced by the parental dominance subclass effect. However, it seems also to support the hypothesis that results from Model $1 \mathrm{I} .2$ were closer to reality because original groups may not have only masked heterosis but also some dominance variance.

Other authors (e.g., Elzo and Famula, 1985) used alternative methods to model additive and nonadditive (co)variances, but most research has concentrated on the modeling of mean breed interaction and its use in commercial situations (e.g., Gregory et al., 1994).

Our results showed the feasibility and the advantage of an individual dominance approach based on sire-dam combinations compared with the modeling of heterosis. Also, use of specific combining ability as described by Henderson (1989) might permit the exploitation of the observed dominance variance in commercial situations, upgrading, or purebred populations.

\section{Implications}

Our results indicated that dominance seems to exist for postweaning gain in U.S. Limousin. Dominance variances relative to phenotypic and additive variances were very important and higher than most other recent estimates. Our results showed that growth traits seem to be excellent candidates for dominance variance. In the future, these traits may also be good candidates for estimation of specific combining ability. This approach should be superior to using expected heterosis on a breed level in commercial selection because allele interaction is directly modeled on a siredam base independently from breed origin. Therefore, expected gains through the use of specific combination ability as a part of the mating selection criteria for growth might be high.

\section{Literature Cited}

Culbertson, M. S., J. W. Mabry, I. Misztal, N. Gengler, J . K. Bertrand, and L. Varona. 1998. Estimation of dominance variance in purebred Yorkshire swine. J. Anim. Sci. 76:448-451.

Elzo, M. A., and T. R. Famula. 1985. Multibreed sire evaluation procedures within a country. J. Anim. Sci. 60:942-952.

Gengler, N., L. D. Van Vleck, M. D. MacNeil, I. Misztal, and F. A. Pariacote. 1997. Influence of dominance relationships on the estimation of dominance variance with sire-dam subclass effects. J. Anim. Sci. 75:2885-2891.

Gregory, K. E., L. V. Cundiff, R. M. Koch, M. E. Dikeman, and M. Koohmaraie. 1994. Breed effects and retained heterosis for growth, carcass, and meat traits in advanced generations of composite populations of beef cattle. J . Anim. Sci. 72:833-850.

Henderson, C. R. 1989. Prediction of merits of potential matings from sire-maternal grandsire models with nonadditive genetic effects. J . Dairy Sci. 72:2592-2605.

Hoeschele, I., and P. M. VanRaden. 1991. Rapid inversion of dominance relationship matrices for noninbred populations by including sire by dam subclass effects. J . Dairy Sci. 74:557-569.

Lo, L. L., R. L. Fernando, and M. Grossman. 1997. Genetic evaluation by BLUP in two-breed terminal crossbreeding systems under dominance. J. Anim. Sci. 75:2877-2884.

Misztal, I. 1997. Estimation of variance components with large-scale dominance models. J. Dairy Sci. 80:965-974.

Misztal, I., T. J . Lawlor, and R. L. Fernando. 1997a. Studies on dominance models by Method $\Re$ for stature of Holsteins. J. Dairy Sci. 80:975-978.

Misztal, I., T. J. Lawlor, and N. Gengler. 1997b. Relationships among estimates of inbreeding depression, dominance and additive variance for linear traits in Holsteins. Genet. Sel. Evol. 29:319-326.

Reverter, A., B. L. Golden, R. M. Bourdon, and J . S. Brinks. 1994. Method $\Re$ variance components procedure: Application on the simple breeding value model. J. Anim. Sci. 72:2247-2253.

Rodríguez-Almeida, F. A., L. D. Van Vleck, R. L. Willham, and S. L. Northcutt. 1995. Estimation of non-additive genetic variances in three synthetic lines of beef cattle using an animal model. J . Anim. Sci. 73:1002-1011.

Sölkner, J ., and J . W. J ames. 1990. Optimum design of crossbreeding experiment, 2: Optimum relationship structures of animals within and between genetic groups. J . Anim. Breed. Genet. 107: 411-420.

VanRaden, P. M. 1992. Accounting for inbreeding and crossbreeding in genetic evaluation of large populations. J. Dairy Sci. 75: 3136-3144. 